\title{
Monomeric green fluorescent protein as a protein standard for small angle scattering
}

\author{
Daniel P. Myatt*, Louise Hatter, Sarah E. Rogers, Ann E. Terry and Luke A. Clifton \\ ISIS Spallation Neutron Source, Rutherford Appleton Laboratory, Harwell Science and Innovation \\ Campus, Didcot, Oxfordshire, OX11 OQX, UK
}

\begin{abstract}
Protein small angle scattering (SAS) has become increasing important in structural biochemistry, due to the increased performance and specification of new instruments and advances in the software and hardware used to analyse the data. Whilst all of this is encouraging, there is a lack of standardised experimental methodology within the community. Although a number of protein standards are currently used in SAS experiments to allow accurate molecular weight determination, each has specific advantages and disadvantages. We therefore propose the use of a mutated monomeric enhanced green fluorescent protein, as a protein standard, abbreviated to m-eGFP. It has a number of advantages over the currently used protein standards, for example it is cheap and easy to produce. It can be expressed in large amounts $(>40 \mathrm{mg} / \mathrm{L})$ in both hydrogenated and deuterated form. The mutation means it is highly monodisperse and GFP being a beta-barrel structure is thermodynamically stable over a number of days, giving highly reproducible results. We therefore believe m-eGFP is a good protein standard for small angle scattering (SAS).
\end{abstract}

Keywords: Green fluorescent protein, small angle scattering, protein standard, biophysics, small angle neutron scattering, small angle X-ray scattering

\section{Abbreviations}

\begin{tabular}{ll}
$\sigma$ & 1 standard deviation \\
$\AA$ & angstrom \\
AUC & analytical ultra-centrifugation \\
BSA & bovine serum albumin \\
$\mathrm{D}_{2} \mathrm{O}$ & deuterium oxide \\
$\mathrm{ddH}_{2} \mathrm{O}$ & double distilled water \\
$\mathrm{eGFP}$ & enhanced GFP \\
$\mathrm{GFP}$ & green fluorescent protein \\
$\mathrm{HSA}$ & human serum albumin \\
$\mathrm{I}(0)$ & intensity at zero angle \\
$\mathrm{kDa}$ & kilodaltons \\
$\mathrm{K}_{\mathrm{d}}$ & binding affinity \\
$\mathrm{m}-\mathrm{eGFP}$ & monomeric eGFP \\
$\mathrm{MS}$ & mass spectrometry \\
$\mathrm{M}_{\mathrm{w}}$ & molecular weight \\
\hline
\end{tabular}

${ }^{*}$ Corresponding author. E-mail: daniel.myatt@gmail.com. 


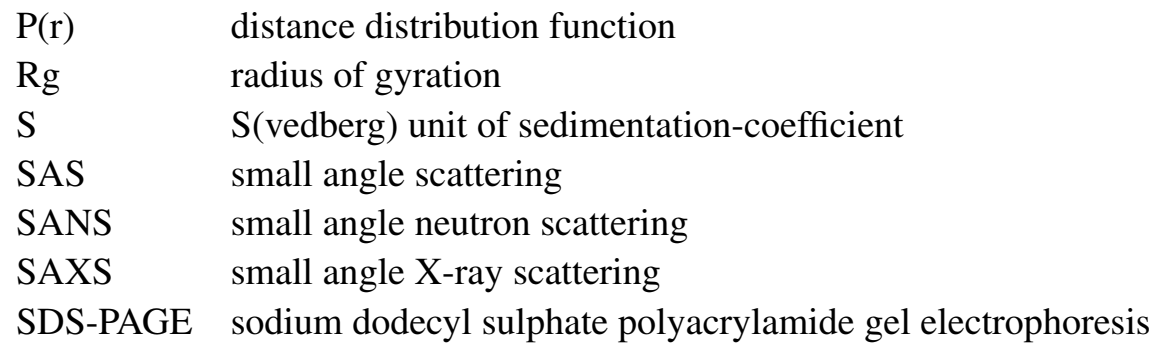

\section{Introduction}

Small angle scattering (SAS) using either X-rays or neutrons is a powerful technique [1,2], which requires accurate standard calibration to allow the determination of the molecular weight $\left(\mathrm{M}_{\mathrm{w}}\right)$ and volume of biomolecules, most commonly proteins [3,4]. Proteins can either be calibrated by comparison to a known protein standard [5,6] or by placing on an absolute scale versus water [7]. The calibration of proteins can be described using the following equation:

$$
\mathrm{I}_{\text {prot }}(0)=\mathrm{I}_{\text {stan }}(0) \frac{\mathrm{C}_{\text {prot }} \times \mathrm{M}_{\text {prot }}}{\mathrm{C}_{\text {stan }} \times \mathrm{M}_{\text {stan }}}
$$

Where, $\mathrm{I}(0)_{\text {prot }}$ and $\mathrm{I}(0)_{\text {stan }}$ (arbitrary units) are the scattering intensities at zero angle of the protein of interest and the protein standard, $\mathrm{c}_{\text {prot }}$ and $\mathrm{c}_{\text {stan }}$ are the concentrations (in (M)oles), of the protein of interest and the protein standard, and $\mathrm{M}_{\text {prot }}$ and $\mathrm{M}_{\text {stan }}$ are the molecular weights $\left(\mathrm{M}_{\mathrm{w}}\right.$ 's) of the protein of interest and the protein standard, respectively (in kilodaltons $(\mathrm{kDa})$ ). A number of proteins have been used as calibration standards, the four main ones being: i) lysozyme [6], ii) bovine (BSA) [6,8] or human serum albumin (HSA) [9] and iii) glucose isomerase [5]. For proteins to be considered as a calibration standard they need a number of attributes, specifically being; i) cheap and abundantly available, ii) monodisperse and iii) thermodynamically stable over time, so giving reproducible and expected results, most commonly using Guinier analysis to determine results such as radius of gyration $(\mathrm{Rg})$ and intensity at zero angle $\mathrm{I}(0)[4,10]$. The two classically used protein standards are lysozyme and BSA $[6,8]$. Both proteins have specific problems. For example, lysozyme has a small molecular weight of only $14.3 \mathrm{kDa}$, making it a weak scatterer at routine small angle scattering concentrations [6]. BSA and also HSA have aggregation problems due to the oxidation of disulphide bond linkages over time causing oligomerisation [11] and are also sensitive to aggregation by ionizing radiation [12]. More recently, Kozak et al. [5] suggested glucose isomerase from Streptomyces rubiginosus as a potential standard. It has good stability properties overtime and to radiation. Although, as a tetramer of $173 \mathrm{kDa}$ it is quite large compared to many proteins of interest [13]. We therefore propose the use of monomeric enhanced green fluorescent protein (m-eGFP). GFP is a $26.9 \mathrm{kDa}$ monomeric 11 -strand beta barrel and like many beta barrels it is extremely thermodynamically stable [14-17]. Enhanced GFP (eGFP) has been mutated to further increase its quantum yield and fluorescence extinction co-efficiency $(\varepsilon)$ over standard GFP [18,19]. Standard eGFP is known to homo-dimerise with a binding affinity of $100 \mu \mathrm{M}[17,20]$. A binding affinity at this level is problematic for protein concentrations commonly used in small angle scattering (i.e. $1-10 \mathrm{mg} / \mathrm{mL}$ ), as it results in significant populations of monomers and dimers. This makes easy analysis as a protein standard far from ideal. Fortunately e-GFP can be mutated at a specific amino acid from an alanine to a lysine (A206K) on its dimerization interface $[17,21]$. This mutation is known 
to disrupt the dimerization interface, reducing the dimerization binding affinity $\left(\mathrm{K}_{\mathrm{d}}\right) 740$-fold to $74 \mathrm{mM}$ $[17,21,22]$. At a binding affinity of this level, with the protein concentration commonly used in SAS $(1-10 \mathrm{mg} / \mathrm{mL}$ ) over $99 \%$ of the protein is monomeric. Utilising SAXS, SANS, mass spectrometry (MS) and analytical ultracentrifugation (AUC) experiments alongside SDS-PAGE gels, we show that m-eGFP is a particularly good small angle scattering protein standard. It is easy to express in large amounts in hydrogenous and deuterated media and is therefore cheap to produce. M-eGFP is also highly florescent and amiable to freeze-dried storage and weighing out, which allows for two checks for protein concentration determination, so reducing concentration errors, which have been observed to be significant in other protein concentration assays [23,24].

\section{Materials and methods}

\subsection{Molecular biology and protein expression}

The eGFP plasmid (QBio-GENE - http://www.qbiogene.com/technical/maps/txt/s-pQBI-T7-BFP.txt plus S66T and H67Y mutations) was provided as a gift from Prof. Cameron Neylon (Curtin University, Australia). Mutagenesis of eGFP was performed using an Agilant QuikChange II Site-Directed Mutagenesis kit and the custom sense and antisense primers designed using the Agilant QuikChange Primer Design site (http://www.genomics.agilent.com/primerDesignProgram.jsp). m-eGFP was produced by a single amino acid mutation at amino acid position 206 (A206K), specifically an alanine (A-GCC) being mutated to a lysine (K-AAA). To confirm mutagenesis sequencing was undertaken by Source Bioscience Ltd. (Oxford, UK) using the purified plasmid DNA and a customised forward sequencing primer of GGTGATGCAACATACGGAAA starting at DNA sequence number 4743 , to allow sequencing of the mutation at sequence number 5256. The plasmid was transformed either into BL21(DE3) E. coli cells and grown in LB media to produce hydrogenous protein or Slantes buffer OD-5 E. coli ${ }^{2} \mathrm{H}$ media (Silantes $\mathrm{GmbH}$, Germany) for deuterated protein in a BioFlo 110 Bioreactor (New Brunswick, UK) to an $\mathrm{OD}_{600}$ of 1.2 , then induced with $0.5 \mathrm{mM}$ IPTG for $4 \mathrm{hrs}$ at $37^{\circ} \mathrm{C}$. The cells were then harvested at $3000 \mathrm{rpm}$ in F8S (Thermo Sorvell ${ }^{\mathrm{TM}}$ ) centrifuge tubes. The cells were lysed using Bugbuster ${ }^{\mathrm{TM}}$ (Novagen, UK) and 5 minutes ON/OFF 10 second cycles of sonication. The lysate was passed through a Colbolt IMAC Hitrap $^{\mathrm{TM}}$ column (General Electric Healthcare, UK) and the protein was eluted by increasing the imidazole concentration to $200 \mathrm{mM}$ in a Tris $\mathrm{pH} 7.5,150 \mathrm{mM} \mathrm{NaCl}$ buffer. After purification the 5-His tag was enzymatically cleaved using the Sortase A enzyme at the LPXTG motif (see Supplementary Material Fig. 1) and the protein was then dialysed into a $20 \mathrm{mM}$ Tris, $150 \mathrm{mM} \mathrm{NaCl}, \mathrm{pH} 7.5$ buffer in $\mathrm{ddH}_{2} \mathrm{O}$ before experimentation.

\subsection{SDS-PAGE gels}

A $10 \mu \mathrm{L}$ sample of $10 \mu \mathrm{M}$ eGFP and m-eGFP was run alongside a Sigma Wide range marker (Sigma Aldrich, UK) at $150 \mathrm{~V}$ on a $12 \%$ SDS PAGE Tris-gels using a Bio-Rad Mini Protean (Biorad, UK) electrophoresis at $298 \mathrm{~K}$. The gel was stained in Biosafe ${ }^{\mathrm{TM}}$ Coomassie blue (Biorad, UK).

\subsection{Mass spectrometry}

Mass spectrometry was performed on a Micromass Q-Tof Micro Mass spectrometer (Waters, UK) on a $10 \mu \mathrm{M}$ hydrogenous $\mathrm{m}$-eGFP sample in $20 \mathrm{mM}$ phosphate and $150 \mathrm{mM} \mathrm{NaCl}$ at $\mathrm{pH} 7.5$ in $\mathrm{ddH}_{2} \mathrm{O}$. 


\subsection{UV absorption}

The concentration of m-eGFP was determined by its $\mathrm{A}_{280}$ absorption value. Samples were measured using an Eppendorf microvolume cuvette on a GeneQuant 1300 (General Electric Healthcare, UK) spectrophotometer. M-eGFP concentrations were determined using a calculated extinction co-efficient of $22,000 \mathrm{M}^{-1} \mathrm{~cm}^{-1}$ at $\mathrm{A}_{280}[16,17]$.

\subsection{Analytical ultracentrifugation}

Sedimentation velocity experiments were conducted at $20{ }^{\circ} \mathrm{C}$ and $129,024 \mathrm{~g}$ (RCF) in a Beckman XL-I analytical ultracentrifuge and Rayleigh interference data was recorded for 999 scans at 1 minute intervals. The resulting concentration distributions were processed exactly the same for each spectra and analysed by the SEDFIT program [25] to obtain $\mathrm{c}(\mathrm{s})$ - $\mathrm{s}$ distributions for hydrogenous eGFP and $\mathrm{m}$-e GFP at 1,5 and $10 \mathrm{mg} / \mathrm{mL}$ in a $20 \mathrm{mM}$ Phosphate, $150 \mathrm{mM} \mathrm{NaCl}$ buffer at $\mathrm{pH} 7.5$ in $\mathrm{ddH}_{2} 0$ conducted at $20{ }^{\circ} \mathrm{C}$. The experimental hydrodynamic parameters were compared to theoretical parameters calculated using the GFP crystal structure (Pdb: 1EMA) [14] in the HYDROPRO software program [26].

\subsection{SAXS data collection}

SAXS measurements of a hydrogenous m-eGFP protein in hydrogenous buffer were performed at three different concentrations $(1,5$ and $10 \mathrm{mg} / \mathrm{mL})$ on the B21 beamline at the Diamond Light Source Ltd. [27] (UK) using the automated BIOSAXS robot for sample loading at $15^{\circ} \mathrm{C}$. B21 was operated at a fixed camera length of $3.9 \mathrm{~m}$ and an energy of $12.4 \mathrm{keV}$ to collect data between 0.015 and $0.3 \AA^{-1}$. The data was collected on a $2 \mathrm{M}$ Pilatus detector (Dectris, UK). The data from the two dimensional area detector was converted into one-dimensional intensity profiles by radial averaging. The data was then corrected to allow for sample transmission and background scattering (using $20 \mathrm{mM}$ Tris, $150 \mathrm{mM}$ $\mathrm{NaCl}$ at $\mathrm{pH} 7.5$ in $\mathrm{ddH}_{2} \mathrm{O}$ as a reference). The data were processed using the DAWN software package (Diamond Light Source Ltd., UK) [28].

\subsection{SANS data collection}

SANS experiments of hydrogenous m-eGFP protein in deuterated buffer and deuterated protein in hydrogenous buffer at three different concentrations $(1,5$ and $10 \mathrm{mg} / \mathrm{mL})$ were conducted at the ISIS Spallation Neutron Source (UK) using the LOQ and SANS2d Instruments [29,30]. LOQ is a time of flight (TOF) SANS instrument with a two-dimensional $64 \mathrm{~cm}$ by $64 \mathrm{~cm} 3 \mathrm{He}-\mathrm{CH}_{4}$ ORDELA detector with $5 \mathrm{~mm}$ resolution. Neutron wavelengths of between 2.2 and $10 \AA$ were utilised and a distance of $4.1 \mathrm{~m}$ between sample position and the detector was used to measure scattering profiles. SANS2d is also a time of flight (TOF) instrument with two two-dimensional $96.5 \mathrm{~cm}$ by $96.5 \mathrm{~cm} 3 \mathrm{He}-\mathrm{CF}_{4}$ filled ORDELA detectors with a $5 \mathrm{~mm}$ resolution. Neutron wavelength between 2 and $14 \AA$ were utilised and a distance of between 2 and $12 \mathrm{~m}$ between sample position and detector were used to measure the scattering profile. Both instruments used absolute intensities for scattering determined using a partially deuterated polymer standard. All measurements were carried out at room temperature in sealed $1 \mathrm{~mm}$ pathlength quartz cuvettes (Hellma Analytics) during data collection. The data from the two dimensional area detector was converted into one-dimensional intensity profiles by radial averaging. The SANS data was then corrected to allow for sample transmission and background scattering (using either $20 \mathrm{mM}$ Tris, $150 \mathrm{mM} \mathrm{NaCl}$ at $\mathrm{pH} / \mathrm{pD} 7.5$ in $\mathrm{ddH}_{2} \mathrm{O}$ for deuterated protein samples or $\mathrm{D}_{2} \mathrm{O}$ for hydrogenous protein 
samples as a reference).The data was processed using the Mantid software package (ISIS Neutron and Muon Source, UK) [31].

\subsection{SAS data analysis}

For SANS measurements, theoretical estimates of the scattering length density of the protein and estimates of its intensity at zero angle $\mathrm{I}(0)$ were performed using the Biological Scattering Length Density Calculator (http://psldc.isis.rl.ac.uk/Psldc/). For all SAS measurements, Guinier analysis was performed using the ISIS Biological scattering Guinier webtool (http://psldc.isis.rl.ac.uk/Guinier). Data was taken in line with globular proteins from a minimum $\mathrm{q} \times \mathrm{Rg}=0.5$ to a maximum $\mathrm{q} \times \mathrm{Rg}=1.3$. Distance distribution functions $(\mathrm{P}(\mathrm{r}))$ were calculated using GNOM [32-35]. Both methods allow the determination of the radius of gyration $(\mathrm{Rg})$ and the zero angle scattering intensity $(\mathrm{I}(0))$ of the sample. Distance distribution functions $(\mathrm{P}(\mathrm{r}))$ also provide information on other parameters; such as the maximum diameter $\left(D_{\max }\right)$ and overall shape of the particle in the sample $[4,36]$. The experimental data was compared to the available X-ray crystal structure of monomeric green fluorescent protein Pdb: 1EMA, using CRYSOL [37].

\section{Results and discussion}

The SDS-PAGE gel (see Fig. 1) shows a single band just below the $29 \mathrm{kDa}$ marker as expected from the calculated molecular weight of full-length hydrogenous m-eGFP $(28.6 \mathrm{kDa}$ - see Supplementary Material Fig. 1 - for the full coding sequence). No other significant protein bands were observed on the SDS-PAGE gel, indicative of a highly purified sample. The mass spectrum (see Fig. 2) of the same sample shows one single peak with a molecular weight of $28.6 \mathrm{kDa}$, corresponding to the hydrogenous m-eGFP. As a final analysis of sample purity and homogeneity, three concentrations of m-eGFP $(1,5$ and $10 \mathrm{mg} / \mathrm{ml})$ were run in an analytical ultracentrifuge in a sedimentation velocity experiment

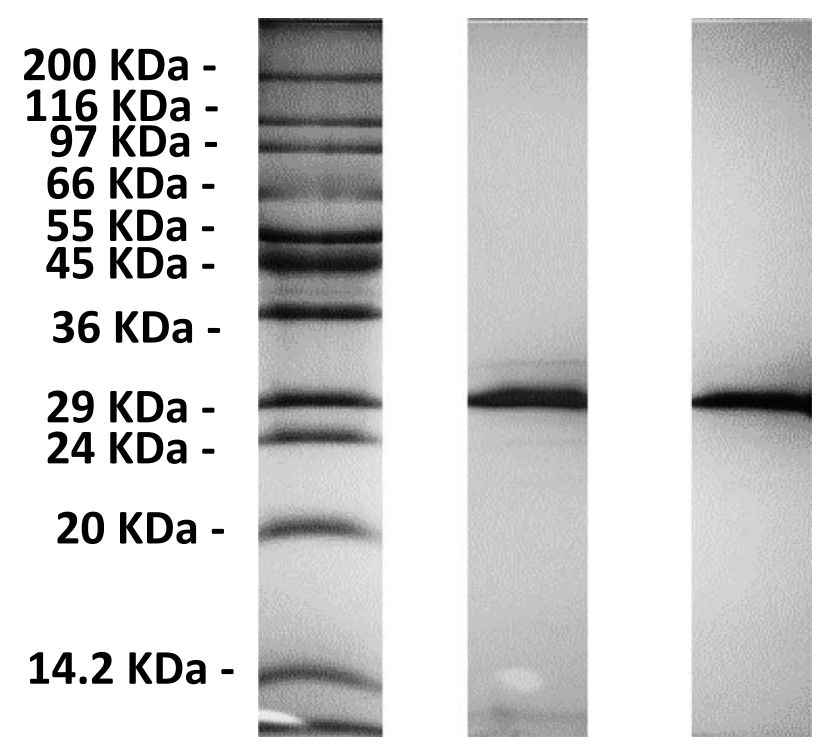

Fig. 1. A 12\% SDS-PAGE of a eGFP (middle) and m-eGFP (right) run alongside a Sigma Wide Range marker (left). 


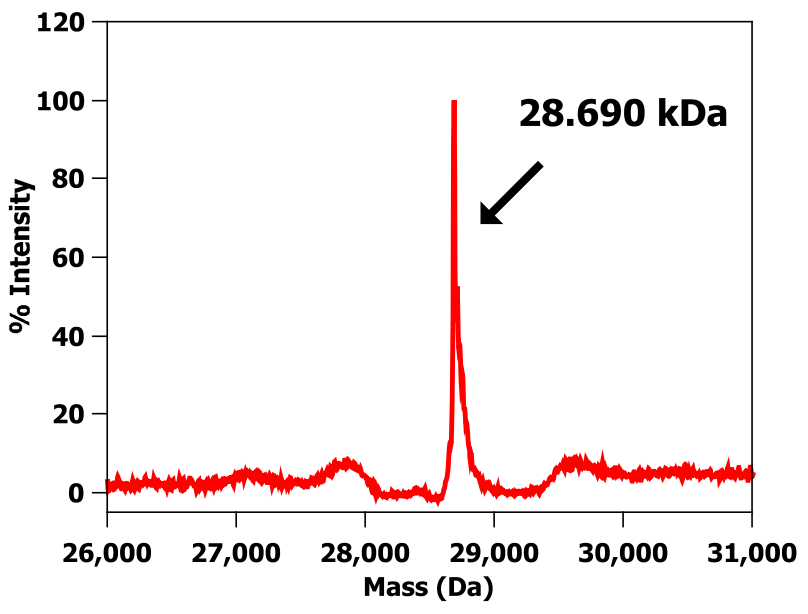

Fig. 2. A mass spectrum of a hydrogenous m-eGFP protein sample in hydrogenous buffer. Protein buffer was $20 \mathrm{mM}$ phosphate, $150 \mathrm{mM} \mathrm{NaCl}$ at $\mathrm{pH} 7.5$.

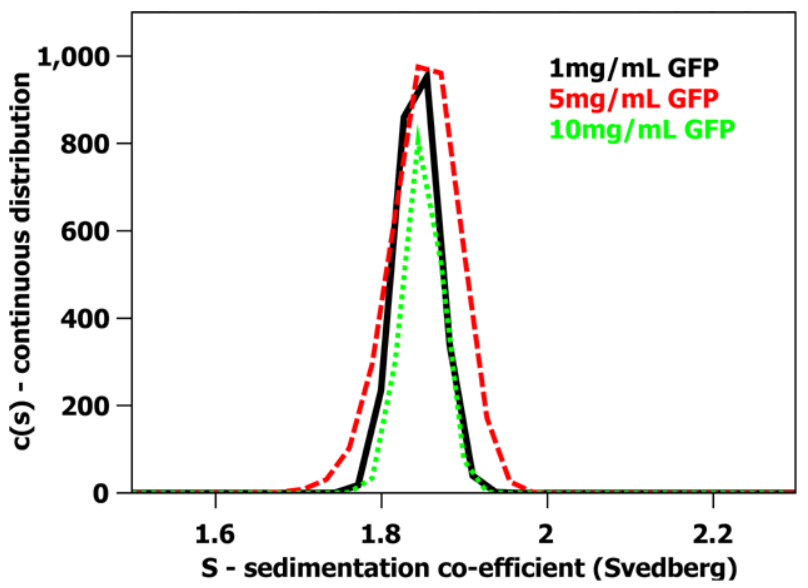

Fig. 3. A sedimentation velocity analytical ultracentrifugation experiment using Rayleigh interference optics of hydrogenous $\mathrm{m}$-eGFP at 1 (black - solid line), 5 (red - dash line) and $10 \mathrm{mg} / \mathrm{mL}$ (green - dot line) concentrations. The sedimentation coefficient distribution was obtained using SEDFIT analysis [25]. The sample was run in a $20 \mathrm{mM}$ phosphate, $150 \mathrm{mM} \mathrm{NaCl}$ buffer in $\mathrm{ddH}_{2} \mathrm{O}$ conducted at $20^{\circ} \mathrm{C}$ and $129,024 \mathrm{~g}(\mathrm{RCF})$.

using Rayleigh interference optics (see Fig. 3). As expected the m-eGFP showed only one peak at 1.9 $\mathrm{S}$ (vedberg) at each of the three concentrations, this is again indicative of a monodisperse, high purity sample. The standard, non-mutated, eGFP sample (Supplementary Material - Fig. 2) was also ran at the same three concentrations $(1,5$ and $10 \mathrm{mg} / \mathrm{ml})$ and showed two distinct populations of species in slow exchange [38]. The two species were confirmed as being the monomer at $1.9 \mathrm{~S}$ and the dimer at $2.5 \mathrm{~S}$, by calculating theoretical Svedberg values for the monomer and dimer of eGFP using the HYDROPRO software [26] and the crystal structures of both proteins (Pdb: 1EMA [14] and 1GFL [15], respectively see Fig. 4 and Supplementary Material Fig. 3) As expected the dimer increased as a percentage of the total concomitant to increasing protein concentration in accordance with a binding affinity of $100 \mu \mathrm{M}$ (see Supplementary Fig. 1) [17]. The dimer made up 39, 60 and 70\% of the total species at 1, 5 and $10 \mathrm{mg} / \mathrm{mL}$ respectively (See Supplementary Material Equation 1 and Table 1 for the full derivation of 


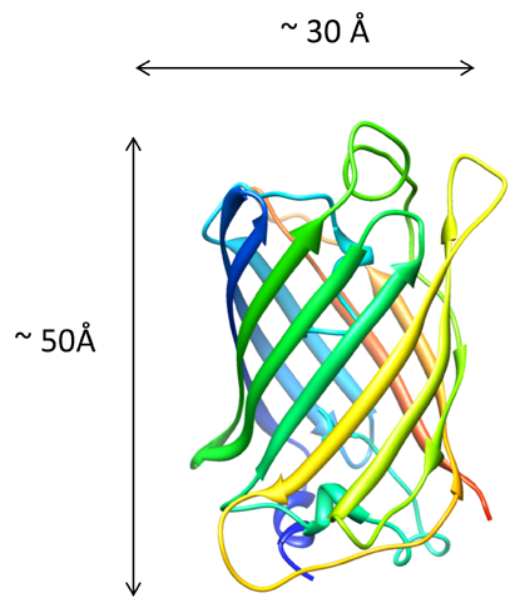

Fig. 4. The crystal structure of Green Fluorescent Protein (GFP) monomer - Pdb: 1EMA [14].

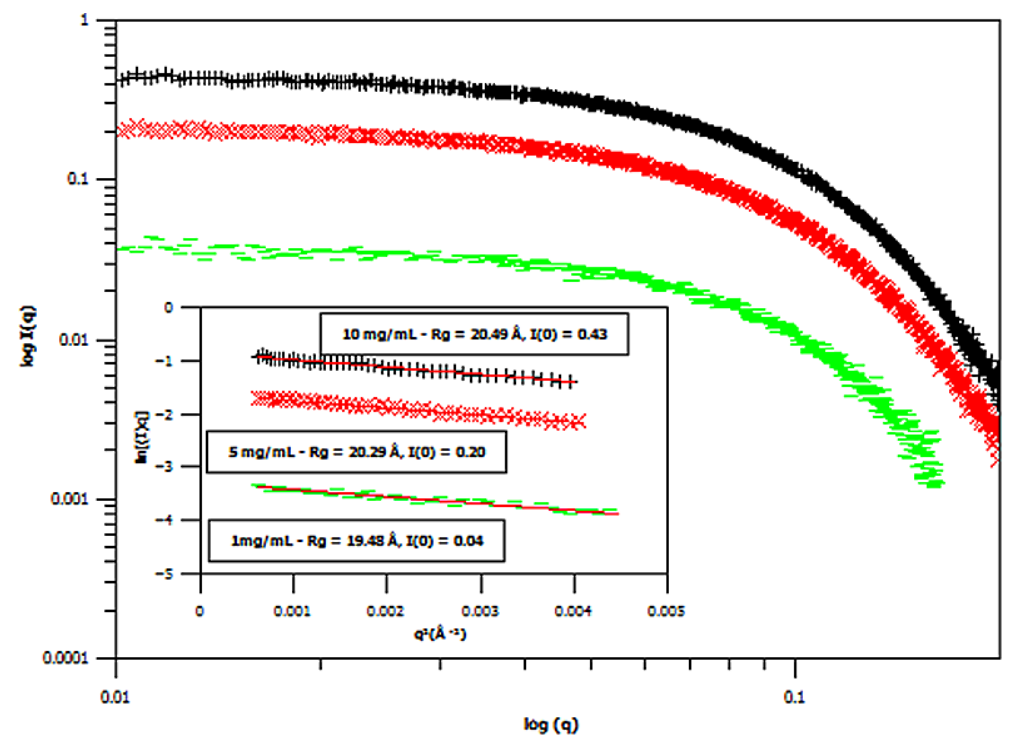

Fig. 5. Small angle X-ray scattering (SAXS) curves of three different concentrations of hydrogenous m-GFP in hydrogenous buffer, at $1 \mathrm{mg} / \mathrm{mL}$ (green - flat line), $5 \mathrm{mg} / \mathrm{mL}$ (red - diagonal cross) and $10 \mathrm{mg} / \mathrm{mL}$ (black - cross line) concentrations. The spectra is shown in $\log \mathrm{I}(\mathrm{q})$ versus $\log \mathrm{q}$. Data points are plotted where the error bars are less than $5 \%$ of the data point value. The protein is in $20 \mathrm{mM}$ Phosphate, $150 \mathrm{mM} \mathrm{NaCl}$ buffer at $\mathrm{pH} 7.5 \mathrm{in} \mathrm{ddH}_{2} \mathrm{O}$. The inset show the corresponding Guinier plots of the SAXS scattering curves, with the calculated radius of gyration $(\mathrm{Rg})$ and intensity at zero angle $(\mathrm{I}(0))$.

monomer: dimer binding and the theoretical population percentages versus AUC experimental results). After mutation of e-GFP, to monomeric eGFP (m-eGFP), disrupting its dimersation interface, the dimersation binding affinity increases 740 fold to $74 \mathrm{mM}$ [17], this means the monomer is over $99 \%$ of m-eGFP at the experimental concentrations (see Supplementary Material Table 1).

Three concentrations of m-eGFP were then run in the SAXS and SANS experiment to determine the intensity at zero angle $\mathrm{I}(0)$ and radius of gyration $(\mathrm{Rg})$ of m-eGFP (for the results see in Figs 5 and 6 and Supplementary Material Table 2). From the three concentrations in both SAXS and SANS we get consistent radius of gyrations (Rg) within a 95\% confidence level. For SAXS (see Fig. 5), hydrogenous 


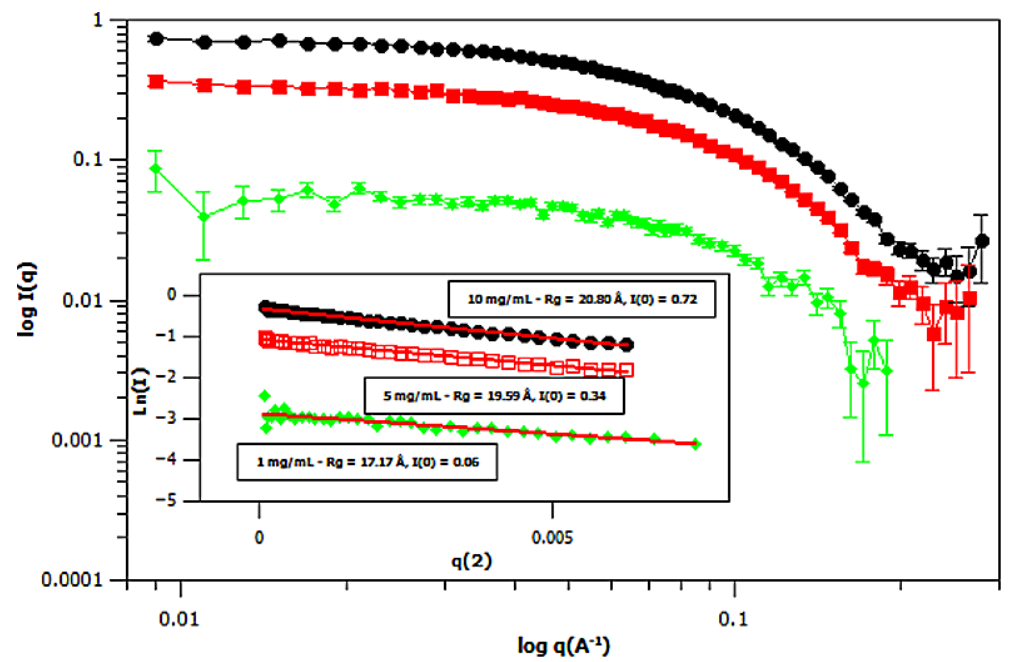

Fig. 6. Small angle neutron scattering (SANS) curves of three different concentrations of deuterated m-GFP in hydrogenous buffer, at $1 \mathrm{mg} / \mathrm{mL}$ (green - diamond), $5 \mathrm{mg} / \mathrm{mL}$ (red - square) and $10 \mathrm{mg} / \mathrm{mL}$ (black - ellipse) concentrations. The spectra is shown in $\log \mathrm{I}(\mathrm{q})$ versus $\log \mathrm{q}$. Data points are plotted where the error bars are less than the value of the data point. The protein is in $20 \mathrm{mM}$ Phosphate, $150 \mathrm{mM} \mathrm{NaCl}$ buffer in $\mathrm{ddH}_{2} \mathrm{O}$. The inset shows a Guinier plots of m-eGFP for the SANS curves with the calculated radius of gyration $(\mathrm{Rg})$ and intensity at zero angle $(\mathrm{I}(0))$.

protein samples in hydrogenous buffer, gave radius of gyrations (Rg's) of 19.48, 20.29 and $20.49 \AA$ (to 2 d.p) for 1,5 and $10 \mathrm{mg} / \mathrm{ml}$ concentrations, respectively. Whilst for SANS (see Fig. 5), deuterated protein samples in hydrogenous buffer, gave radius of gyrations (Rg's) of 17.17, 19.59 and $20.80 \AA$ (to 2 d.p) for 1,5 and $10 \mathrm{mg} / \mathrm{mL}$, repectively. Both the techniques, as expected, are in good agreement, with the $1 \mathrm{mg} / \mathrm{mL}$ value for SAXS and particularly SANS values showing the largest standard deviation away from the mean. The increased noise in SAXS and SANS data at $1 \mathrm{mg} / \mathrm{ml}$ was due to a lower concentration. All of the radius of gyration values are also in good agreement with the CRYSOL [37] model value of $16.98 \AA$ for the smaller crystal GFP structure (Pdb: 1EMA) without the N- and Cterminal tails [14]. Intensity at zero angle $\mathrm{I}(0)$ values were also calculated for both techniques. These values are dependant on a number of parameters including the sample concentration and buffer content (i.e $\mathrm{D}_{2} \mathrm{O}$ percentage for SANS). As expected, the values increased concomitantly with concentration, both in SAXS and SANS. For SAXS (see Fig. 5), a hydrogenous protein sample in hydrogenous buffer gave zero angle intensity $\mathrm{I}(0)$ values of $0.04,0.20$ and $0.43 \mathrm{~cm}^{-1}$ (to 2 d.p) for 1,5 and $10 \mathrm{mg} / \mathrm{mL}$ respectively. Whilst for SANS (see Fig. 5), a deuterated sample in hydrogenous buffer (used to increase the scattering signal by increasing contrast variation) gave zero angle intensity $\mathrm{I}(0)$ values of $0.06,0.34$ and $0.72 \mathrm{~cm}^{-1}$ (to 2 d.p) for 1,5 and $10 \mathrm{mg} / \mathrm{mL}$ respectively. Again, both sets of values are within the $95 \%$ confidence level of standard deviation. The SANS values are in good agreement with rough estimated values of $0.10,0.48$ and $0.96 \mathrm{~cm}^{-1}$ (to 2 d.p) for zero angle intensity $\mathrm{I}(0)$, for a globular protein made using the Biological Scattering Calculator [39] for a 90\% deuterated m-eGFP protein, with $90 \%$ hydrogen exchange in $100 \% \mathrm{ddH}_{2} \mathrm{O}$ buffer.

A distance distribution function $(\mathrm{P}(\mathrm{r}))$ analysis using the $10 \mathrm{mg} / \mathrm{mL}$ SAXS and SANS m-eGFP data was then performed (see Fig. 7). Distance distribution provides a number of complimentary parameters to the Guinier analysis. As well as radius of gyration $(\mathrm{Rg})$ and intensity at zero angle $\mathrm{I}(0)$, other important values such as the particles maximum diameter $\left(\mathrm{D}_{\max }\right)$ and particle shape are also determined [4]. The distance distribution analysis $(\mathrm{P}(\mathrm{r}))$ is indicative of a globular protein of length $\sim 50 \AA$, as shown in the 


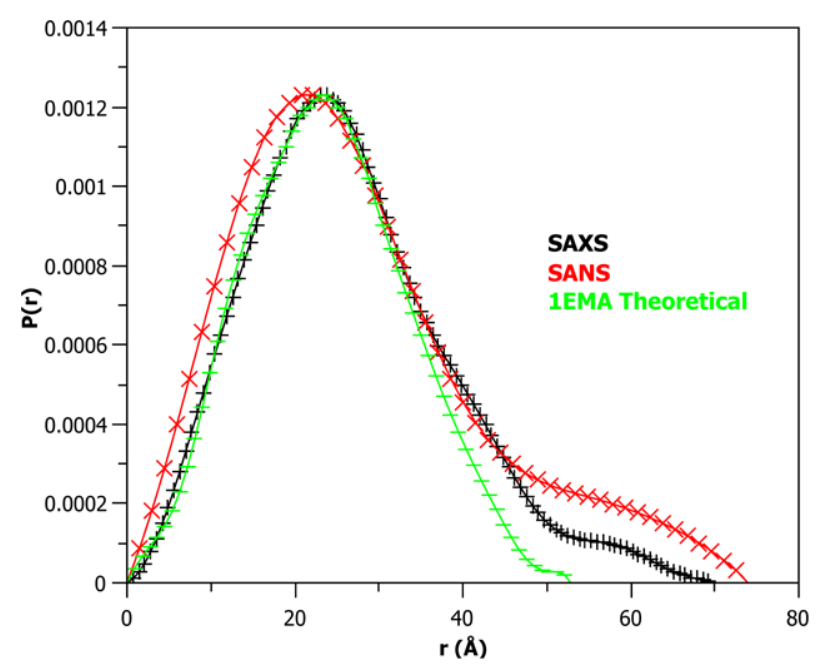

Fig. 7. The distance distribution plot $(\mathrm{P}(\mathrm{r})-\mathrm{r})$ of m-eGFP taken using the SAXS (black - cross), SANS (red - diagonal cross) and the 1EMA theoretical crystal structure (green - flat line) distance distribution. Distance distribution performed using the $10 \mathrm{mg} / \mathrm{mL}$ m-eGFP data shown in Figs 5 and 6 and theoretical crystal structure (Pdb: 1EMA) calculated using Crysol [37].

theoretical GFP crystal structure (see Fig. 7 - green line). The increased tail observed in the experimental SAXS and SANS data (see Fig. 7 - black and red lines, respectively) is from the N-and C-terminals of the particles, not present in the GFP crystal structure data [14] (Fig. 7 - green line). The experimental values obtained (Fig. 7 - black and red line) are therefore in good agreement with the theoretical data calculated from the protein data bank structure (Pdb: 1EMA [14] - Fig. 7 - green line).

A key factor in developing a new biological small angle scattering standard is the particles stability over time. To test m-eGFP's stability, SANS data was taken for a hydrogenous m-eGFP protein sample in deuterated buffer over 1,15 and 30 days at three concentrations $(1,5$ and $10 \mathrm{mg} / \mathrm{mL})$. A Guinier analysis of the data was then performed to determine any changes in the zero angle intensity $\mathrm{I}(0)$ and radius of gyration $\left(\mathrm{R}_{\mathrm{g}}\right)$ at each concentration and time point. The results of this analysis (see Fig. 8 and Supplementary Material Table 3) give the average radius of gyration $(\mathrm{Rg})$ and intensity at zero angle $(\mathrm{I}(0))$ value of the 9 spectra ( 3 different time points (1, 15 and 30 days) at 3 concentrations $(1,5$ and $10 \mathrm{mg} / \mathrm{mL}$ )). The average radius of gyration ( $\mathrm{Rg}) 18.14 \AA \pm(1 \sigma) 0.82$ (to 2 d.p), and intensity at zero angle $(\mathrm{I}(0))$ value of $0.41 \mathrm{~cm}^{-1} \pm(1 \sigma) 0.03$ (to $2 \mathrm{~d} . \mathrm{p}$ ) are obtained (see Supplementary Material Table 3 full the results). All of the Guinier data points (see Fig. 8) are within the standard $95 \%$ confidence level $(1.96 \sigma)$. The results therefore show no significant deviation from the average values obtained. The results with the largest standard deviation are, as expected, the $1 \mathrm{mg} / \mathrm{mL}$ concentration spectra. This is due to the increased error observed in the spectra from the decreased concentration used. This is particularly apparent for time of flight instruments such as Loq and Sans2d as they have less neutron flux in the Guinier region (ISIS Neutron and Muon Source, UK) [29,30]. There is a small increase in radius of gyration with concentration, this is likely due to the decrease of error in the Guinier region at higher concentrations, although very small amounts of concentration dependent dimerisation/aggregation can not be fully discounted over such a long time period. Also, the intensity at zero angle $\mathrm{I}(0)$ increases concomitantly with concentration as expected. The results (see Fig. 8 and Supplementary Material Table 3) show $\mathrm{m}$-eGFP is not susceptible to the dimerisation and aggregation problems observed in other small angle scattering protein standards, most notable BSA [11,12]. 


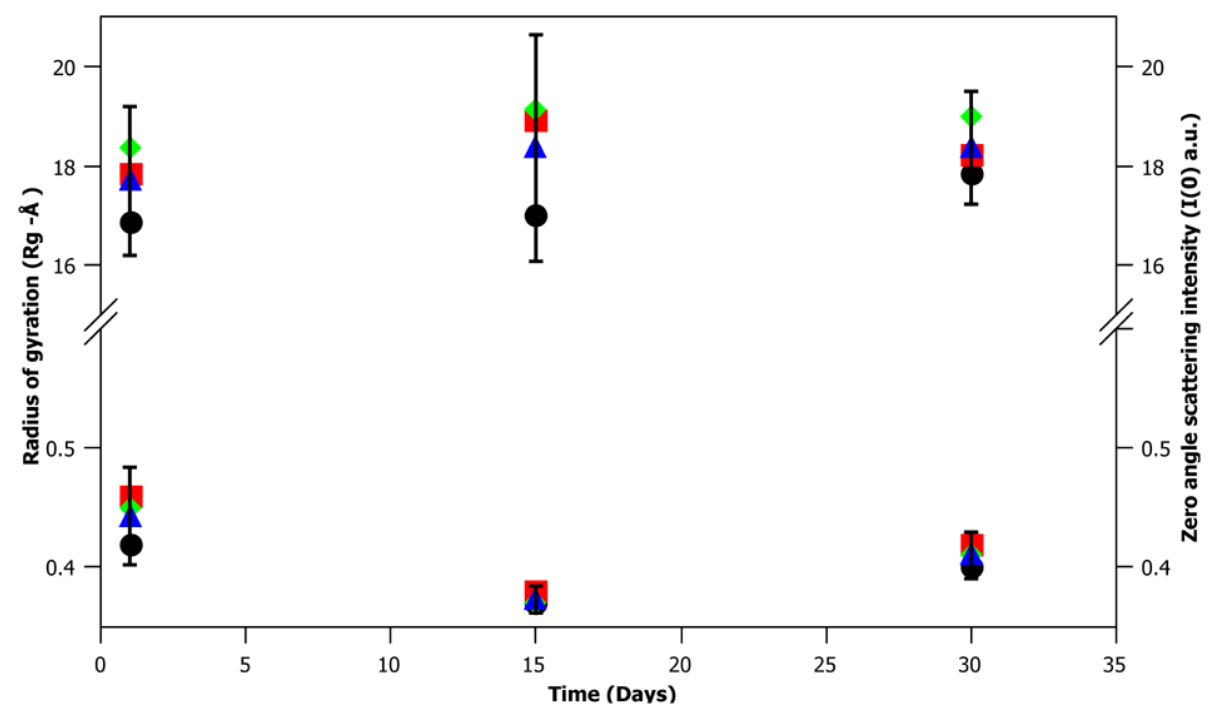

Fig. 8. A time-course at 1,15 and 30 days of a sample of hydrogenous m-eGFP in $\mathrm{D}_{2} \mathrm{O}$ buffer, showing the radius of gyration (Rg) (top) and intensity at zero angle (I(0)) (bottom) of the three different concentrations of m-eGFP $(1,5 \mathrm{and} 10 \mathrm{mg} / \mathrm{mL})$. The cross-points of 1,5 and $10 \mathrm{mg} / \mathrm{mL}$ are denoted by a black ellipse, red square and green diamond, whilst the mean average of the three concentrations is denoted by a blue triangle. The error bars denote the $95 \%$ confidence interval $(1.96 \sigma-$ standard deviation of a standard statistical distribution).

\section{Conclusions}

After the biophysical characterisation shown here, we believe that m-eGFP has all the key characteristics required for use as a protein standard in small angle scattering experiments. Specifically it is easy to obtain, expresses in large amounts in hydrogenous and deuterated media, is highly monodisperse, has high stability over time and also hands storage well. M-eGFP's fluorescent nature also allows for easy concentration determination. We believe the development of m-eGFP as a SAS protein standard is timely, with SAS data becoming increasingly important in structural biology and recent calls for more standardisation of biological SAS data [40-42].

\section{Supplementary data}

Online supplement consisting of figures, equations and tables is available at: http://dx.doi.org/10.3233/ BSI-170167.

\section{Acknowledgements}

The authors wish to thank Prof. Cameron Neylon for providing the e-GFP plasmid (Curtin University), Dr Joanne Nettleship (OPPF, Research Complex at Harwell) for running the mass spectrometer sample and Dr Richard Heenan (ISIS Neutron and Muon Source, UK) for discussion on the calculation of theoretical protein zero angle intensity values for biomolecules. The m-eGFP plasmid construct is available upon request to ISIS Neutron and Muon Source (Oxford, UK). 


\section{Declarations of interest}

The authors declare that they have are no competing interests with the manuscript.

\section{Funding information}

Funding was provided in-house for the relevant consumables and beamtime to DPM as Biological Research Scientist at ISIS Neutron and Muon Source (Oxford, UK).

\section{References}

[1] M.A. Graewert and D.I. Svergun, Impact and progress in small and wide angle X-ray scattering (SAXS and WAXS), Current Opinion in Structural Biology 23 (2013), 748-754. doi:10.1016/j.sbi.2013.06.007.

[2] C.M. Jeffries et al., Preparing monodisperse macromolecular samples for successful biological small-angle X-ray and neutron-scattering experiments, Nature Protocols 11 (2016), 2122-2153. doi:10.1038/nprot.2016.113.

[3] E. Mylonas and D.I. Svergun, Accuracy of molecular mass determination of proteins in solution by small-angle X-ray scattering, Journal of Applied Crystallography 40 (2007), s245-s249. doi:10.1107/S002188980700252X.

[4] D.I. Svergun et al., Small Angle X-Ray and Neutron Scattering from Solutions of Biological Macromolecules, 1st edn, Oxford University Press, Oxford, 2013.

[5] M. Kozak, Glucose isomerase from Streptomyces rubiginosus - Potential molecular weight standard for small-angle X-ray scattering, Journal of Applied Crystallography 38 (2005), 555-558. doi:10.1107/S0021889805010472.

[6] M. Hammel et al., Solution structure of human and bovine $\beta 2$-glycoprotein I revealed by small-angle X-ray scattering, Journal of Molecular Biology 321 (2002), 85-97. doi:10.1016/S0022-2836(02)00621-6.

[7] D. Orthaber et al., SAXS experiments on absolute scale with Kratky systems using water as a secondary standard, Journal of Applied Crystallography 33 (2000), 218-225. doi:10.1107/S0021889899015216.

[8] S. Akiyama, Quality control of protein standards for molecular mass determinations by small-angle X-ray scattering, Journal of Applied Crystallography 43 (2010), 237-243. doi:10.1107/S002188981000138X.

[9] S. Skou et al., Synchrotron-based small-angle X-ray scattering of proteins in solution, Nature Protocols 9 (2014), 17271739. doi:10.1038/nprot.2014.116.

[10] A. Guinier, La diffraction des rayons $X$ aux très petits angles: application à l'étude de phénomènes ultramicroscopiques, Annales de Physique 11 (1939), 161-237. doi:10.1051/anphys/193911120161.

[11] S.M. Vaiana et al., Irreversible formation of intermediate BSA oligomers requires and induces conformational changes, Proteins: Structure, Function, and Bioinformatics 55 (2004), 1053-1062. doi:10.1002/prot.20074.

[12] Y. Cho, J.S. Yang and K.B. Song, Effect of ascorbic acid and protein concentration on the molecular weight profile of bovine serum albumin and $\beta$-lactoglobulin by $\gamma$-irradiation, Food Research International 32 (1999), 515-519. doi:10. 1016/S0963-9969(99)00127-1.

[13] H.L. Carrell et al., Modes of binding substrates and their analogues to the enzyme D-xylose isomerase, Acta Crystallographica Section D Biological Crystallography 50 (1994), 113-123. doi:10.1107/S0907444993009345.

[14] M. Orm et al., Crystal structure of the Aequorea victoria green fluorescent protein, Science 273 (1996), 1392-1395. doi:10. 1126/science.273.5280.1392.

[15] F. Yang et al., The molecular structure of green fluorescent protein, Nature Biotechnology 14 (1996), 1246-1251. doi:10. 1038/nbt1096-1246.

[16] R.Y. Tsien, The green fluorescent protein, Annual Review of Biochemistry 67 (1998), 509-544. doi:10.1146/annurev. biochem.67.1.509.

[17] M. Chalfie and S. Kain, Green Fluorescent Protein: Properties, Applications, and Protocols, Wiley-Interscience, Hoboken, N.J., 2006.

[18] B.P. Cormack et al., FACS-optimized mutants of the green fluorescent protein (GFP), Gene 173 (1996), 33-38. doi:10. 1016/0378-1119(95)00685-0.

[19] T.-T. Yang et al., Optimized codon usage and chromophore mutations provide enhanced sensitivity with the green fluorescent protein, Nucleic Acids Research 24 (1996), 4592-4593. doi:10.1093/nar/24.22.4592.

[20] G.N. Phillips, Structure and dynamics of green fluorescent protein, Curr. Opin. Struct. Biol. 7 (1997), 821-827. doi:10. 1016/S0959-440X(97)80153-4.

[21] D.A. Zacharias, Partitioning of lipid-modified monomeric GFPs into membrane microdomains of live cells, Science 296 (2002), 913-916. doi:10.1126/science.1068539. 
[22] D. von Stetten et al., Structure of a fluorescent protein from Aequorea victoria bearing the obligate-monomer mutation A206K, Acta Crystallographica Section F Structural Biology and Crystallization Communications 68 (2012), 878-882. doi:10.1107/S1744309112028667.

[23] G. Giraudi et al., Inaccuracy of the Bradford method for the determination of protein concentration in steroid-horseradish peroxidase conjugates, Analytica Chimica Acta 337 (1997), 93-97. doi:10.1016/S0003-2670(96)00388-1.

[24] C.V. Sapan et al., Colorimetric protein assay techniques, Biotechnol. Appl. Biochem. 29(Pt. 2) (1999), 99-108.

[25] J. Dam and P. Schuck, Calculating sedimentation coefficient distributions by direct modeling of sedimentation velocity concentration profiles, Meth. Enzymol. 384 (2004), 185-212. doi:10.1016/S0076-6879(04)84012-6.

[26] A. Ortega et al., Prediction of hydrodynamic and other solution properties of rigid proteins from atomic- and residue-level models, Biophysical Journal 101 (2011), 892-898. doi:10.1016/j.bpj.2011.06.046.

[27] Diamond Light Source Ltd. Annual Review 2015/16, n.d. Available at: http://www.diamond.ac.uk/Home/ Corporate-Literature/Annual-Review/Review2016.html.

[28] M. Basham et al., Data analysis WorkbeNch (DAWN), Journal of Synchrotron Radiation 22 (2015), 853-858. doi:10. $1107 /$ S1600577515002283.

[29] R.K. Heenan et al., SANS at pulsed neutron sources: Present and future prospects, Journal of Applied Crystallography 30 (1997), 1140-1147. doi:10.1107/S0021889897002173.

[30] R.K. Heenan, S.M. King, D.S. Turner and J.R. Treadgold, SANS2D at the ISIS second target station, in: Proc. ICANS XVII, 780-785, 2006.

[31] F. Akeroyd et al., Mantid: Manipulation and Analysis Toolkit for Instrument Data, 2013. doi:10.5286/SOFTWARE/ MANTID.

[32] D.I. Svergun, Determination of the regularization parameter in indirect-transform methods using perceptual criteria, Journal of Applied Crystallography 25 (1992), 495-503. doi:10.1107/S0021889892001663.

[33] M.V. Petoukhov et al., ATSAS 2.1 - Towards automated and web-supported small-angle scattering data analysis, Journal of Applied Crystallography 40 (2007), s223-s228. doi:10.1107/S0021889807002853.

[34] M.V. Petoukhov et al., New developments in the ATSAS program package for small-angle scattering data analysis, Journal of Applied Crystallography 45 (2012), 342-350. doi:10.1107/S0021889812007662.

[35] P.V. Konarev et al., PRIMUS: A Windows PC-based system for small-angle scattering data analysis, Journal of Applied Crystallography 36 (2003), 1277-1282. doi:10.1107/S0021889803012779.

[36] D.I. Svergun and M.H.J. Koch, Small-angle scattering studies of biological macromolecules in solution, Reports on Progress in Physics 66 (2003), 1735-1782. doi:10.1088/0034-4885/66/10/R05.

[37] D. Svergun et al., CRYSOL - A program to evaluate X-ray solution scattering of biological macromolecules from atomic coordinates, Journal of Applied Crystallography 28 (1995), 768-773. doi:10.1107/S0021889895007047.

[38] P. Schuck, Basic Principles of Analytical Ultracentrifugation, CRC Press, Taylor \& Francis Group, Boca Raton, 2016.

[39] D.P. Myatt, Biological Scattering Tools, 2013. Available at: http://psldc.isis.rl.ac.uk/.

[40] D.A. Jacques and J. Trewhella, Small-angle scattering for structural biology - Expanding the frontier while avoiding the pitfalls, Protein Science 19 (2010), 642-657. doi:10.1002/pro.351.

[41] D.A. Jacques et al., Publication guidelines for structural modelling of small-angle scattering data from biomolecules in solution, Acta Crystallographica Section D Biological Crystallography 68 (2012), 620-626. doi:10.1107/ S0907444912012073.

[42] UK Neutron and Muon Science and User Meeting, Biology user notes, 2015. Available at: http://www.isis.stfc.ac.uk/ news-and-events/uk-neutron-and-muon-science-and-user-meeting-19--21-may-201515286.html. 